\title{
The role of synthesis pathway on the microstructural characteristics of sulfur-carbon composites: X-ray imaging and electrochemistry in lithium battery
}

\author{
Daniele Di Lecce $^{\mathrm{a}, \mathrm{b}, 1}$, Vittorio Marangon ${ }^{\mathrm{c}, 1}$, Wenjia Du ${ }^{\mathrm{a}}$, Dan J.L. Brett ${ }^{\mathrm{a}, \mathrm{b}}$, Paul \\ R. Shearing ${ }^{\mathrm{a}, \mathrm{b}, \stackrel{*}{*}}$, Jusef Hassoun ${ }^{\mathrm{c}, \mathrm{d}, *}$ \\ ${ }^{a}$ Electrochemical Innovation Lab, Department of Chemical Engineering, UCL, London, WC1E 7JE, United Kingdom \\ ${ }^{\mathrm{b}}$ The Faraday Institution, Quad One, Becquerel Ave, Harwell Campus, Didcot, OX11 ORA, United Kingdom \\ ${ }^{\mathrm{c}}$ Department of Chemical and Pharmaceutical Sciences, University of Ferrara, Via Fossato di Mortara 17, 44121, Ferrara, Italy \\ ${ }^{\mathrm{d}}$ National Interuniversity Consortium of Materials Science and Technology (INSTM) University of Ferrara Research Unit, University of Ferrara, Via Fossato di Mortara \\ 17, 44121, Ferrara, Italy
}

\section{H I G H L I G H T S}

- Various composites are made by mixing molten $\mathrm{S}$ and $\mathrm{C}$ or by alcohol dispersion.

- The composite electrodes used in $\mathrm{Li} / \mathrm{S}$ cells include SP carbon black or MWCNTs.

- X-ray CT detects an intimate mixture of micrometric $\mathrm{S}$ and $\mathrm{C}$ in the electrodes.

- The S-C morphology depends on carbon nature and synthesis route.

- The Li-S cells deliver a maximum capacity from 1150 to $1550 \mathrm{mAh} \mathrm{gs}^{-1}$.

\section{A R T I C L E I N F O}

\section{Keywords:}

Lithium sulfur

Multiwalled carbon nanotubes

Carbon black

Sulfur melting

Sulfur dispersion

X-ray tomography
G R A P H I C A L A B S T R A C T

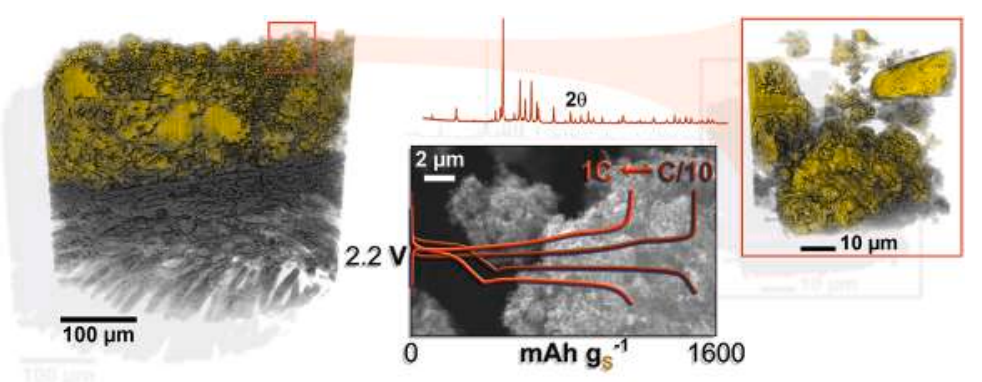

\footnotetext{
* Corresponding author. Department of Chemical and Pharmaceutical Sciences, University of Ferrara, Via Fossato di Mortara 17, 44121, Ferrara, Italy.

** Corresponding author. Electrochemical Innovation Lab, Department of Chemical Engineering, UCL, London, WC1E 7JE, United Kingdom.

E-mail addresses: p.shearing@ucl.ac.uk (P.R. Shearing), jusef.hassoun@unife.it (J. Hassoun).

1 Authors equally contributed.
} 
with values approaching $70 \%$ over 150 cycles. Our multi-disciplinary approach will shed light on significant aspects aiming to enhance the Li-S battery and favor a practical application.

\section{Introduction}

Lithium-sulfur batteries are currently considered one of the most promising alternatives to conventional lithium-ion systems in view of a remarkable theoretical gravimetric energy density (as high as $2600 \mathrm{Wh}$ $\mathrm{kg}^{-1}$ when referred to the $\mathrm{Li}_{2} \mathrm{~S}$ mass) [1]. Furthermore, the favorable characteristics of sulfur, including abundance, widespread availability and modest toxicity, are expected to lower cost and environmental impact of the cell [2]. Despite the encouraging results on the Li-S chemistry reported so far [3], the actual transition of such a promising technology form the laboratory into the market is still hindered by unsolved challenges in the material, electrode and cell design that need to be overcome to ensure suitable configurations with high capacity over long-term cycling [4,5]. Sulfur conversion into solid $\mathrm{Li}_{2} \mathrm{~S}$ evolves via formation of lithium polysulfide intermediates that are soluble in conventional electrolyte media [6], can migrate to the anode side and may react with lithium, thus leading to active material loss, cell efficiency decrease, and cycle life limitation [7]. Therefore, a large part of the Li-S community has been focusing on the investigation of possible strategies to prevent the polysulfide migration towards the anode, principally by implementing nanoporous carbon hosts for sulfur that may limit the cathode dissolution in the electrolyte [8], as well as by developing modified separators and/or interlayers between positive electrode and separator [9-11]. On the other hand, the addition of $\mathrm{LiNO}_{3}$ to the electrolyte has provided lithium-metal protection against undesired reactions with the polysulfides, via formation of a solid electrolyte interphase (SEI) [12]. Moreover, porous carbon cloths [13] and foams [14] suitable as supports for the cathodic film have actually enhanced the reversible electrodeposition of elemental sulfur and assisted the polysulfide conversion, thereby leading to improved performances compared to standard aluminum $[15,16]$. Consequently, electrode film optimization is gaining more attention $[17,18]$ alongside the fine morphological engineering of S-C composites widely investigated in the pioneering Li-S works [19-22]. Indeed, alternative approaches to the conventional sulfur confinement into nanostructured carbon matrices [23], possibly dealing with binder and cell configuration improvements [18] or adopting semi-liquid configurations based on the soluble active material [24], might actually simplify electrode manufacture. In this regard, the simple mixing of micrometric elemental sulfur and carbon may be suitable for an efficient electrochemical process in the cell [25], although the electrode architecture may play a key role in favoring the conversion reaction within a wide current range [26]. In spite of the outstanding performances reported in the literature that benefit from a cathode nanoengineering [27], sulfur impregnation pathways based on melting [25,28,29], crystallization from an organic solution [30], and solvothermal permeation [31] into commercial carbons offer the advantage of being relatively straightforward and ensuring adequate electrochemical results in optimized configurations. Hence, understanding the interplay between the carbon morphology [28,32], the cathodic film microstructure [18], and the battery performance appears to be a crucial step to mitigate the various shortcomings in the current Li-S cell aiming at practical applications [26]. A breakthrough in this challenge may be achieved by employing high-resolution three-dimensional (3D) imaging to better correlate cathode features and cycling behavior [33]. Among 3D-imaging techniques, multiscale X-ray computed tomography (CT) sheds light on the spatial distribution of the sulfur particles within the composite electrode by providing qualitative data associated with the attenuation of the incident beam by the various materials [34]. This technique allows a volume reconstruction of the electrode at the nano- and micro-scale and enables a quantitative analysis of the morphological parameters [35]. Therefore, micro- and
nano-CT may advantageously support the various hypothesis suggested by electrochemical measurements as well as by conventional electron microscopy to explain the effects of several parameters, such as the electrode structure, the synthesis route and the carbon nature, on Li-S battery performance [36]. In this work, we investigate the impact of the synthesis pathway on S-C cathode microstructure, which drives the Li-S cell performance in terms of rate capability and capacity retention. We detect the sulfur particles and analyze their size distribution in the electrode film. In detail, we comparatively study sulfur-carbon mixtures in the 70:30 wt ratio, respectively, prepared by versatile approaches involving either the direct mixing of carbon with molten sulfur or the dispersion of the solid precursors in alcohol. Scalable electrodes are obtained by using commercially available carbon sources (i.e., carbon black and multiwalled carbon nanotubes) and are thoroughly investigated by combining X-ray diffraction, electron microscopy, and energy-dispersive X-ray spectroscopy results with X-ray CT imaging at the nano- and micro-scale. Our findings outline possible pathways for achieving composite electrodes with remarkable specific capacity, suitable rate capability, and limited capacity fade.

\section{Experimental}

\subsection{Synthesis of $S-C$ materials}

\subsubsection{Sulfur melting procedure (MP)}

Elemental sulfur ( $\geq 99.5 \%$, Riedel-de Haën) and either super P carbon black (SPC, Timcal) or multi walled carbon nanotubes (MWCNTs, $>90 \%$ carbon basis, D $\times$ L 110-170 $\mathrm{nm} \times 5-9 \mu \mathrm{m}$, Sigma-Aldrich) were mixed in the weight ratio of 70:30, respectively, and heated in a silicon oil thermostatic bath at $120^{\circ} \mathrm{C}$ to melt sulfur. The mixture was vigorously stirred for ca. $2 \mathrm{~h}$ at $120^{\circ} \mathrm{C}$, cooled to room temperature to achieve a solid composite, and subsequently ground in an agate mortar to obtain a fine black powder. The composites prepared via MP using super $\mathrm{P}$ carbon and multi walled carbon nanotubes are indicated as S@SPC-MP and S@MWCNTs-MP, respectively.

\subsubsection{Solvent-assisted procedure (SAP)}

Elemental sulfur ( $\geq 99.5 \%$, Riedel-de Haën) and either super P carbon black (SPC, Timcal) or multi walled carbon nanotubes (MWCNTs, $>90 \%$ carbon basis, D $\times$ L 110-170 $\mathrm{nm} \times 5-9 \mu \mathrm{m}$, Sigma-Aldrich) were dispersed in 2-propanol ( $\geq 99.8 \%$, Sigma-Aldrich) under magnetic stirring in the weight ratio of 70:30, respectively (the solubility of $S$ in lowmolecular weight alcohols at room temperature has been reported to be $<0.1 \mathrm{wt} \%$ [37]). Afterwards, the mixtures were heated up to the boiling point of 2-propanol until full evaporation of the liquid phase, cooled to room temperature, and dried at room temperature under vacuum for $3 \mathrm{~h}$ to remove any possible trace of solvent. Subsequently, the sulfur-carbon precursors were pressed for $30 \mathrm{~s}$ at ca. $3 \mathrm{t} \mathrm{cm}^{2}$ to obtain $14 \mathrm{~mm}$ diameter pellets, which were heated at $120^{\circ} \mathrm{C}$ for $3 \mathrm{~h}$ under air and then ground in an agate mortar after cooling to room temperature. The composites prepared via SAP using super $\mathrm{P}$ carbon and multi walled carbon nanotubes are indicated as S@SPC-SAP and S@MWCNTs-SAP, respectively.

\subsection{Electrode preparation}

Electrode slurries were prepared by dispersing the sulfur-carbon composites (80 wt $\%$ ), super $\mathrm{P}$ carbon as conductive agent (Timcal, 10 $\mathrm{wt} \%$ ), and polyvinilidene fluoride as binder (PVDF 6020, Solef Solvay, $10 \mathrm{wt} \%$ ) in $N$-methyl-2-pyrrolidone (NMP, anhydrous, 99.5\%, SigmaAldrich) through an agate mortar and a pestle. The homogenized slurries were cast on a carbon-cloth foil (GDL ELAT 1400, MTI Corp.) by 
means of a doctor blade. Afterwards, the slurries were heated at $50{ }^{\circ} \mathrm{C}$ under air for about $3 \mathrm{~h}$ to evaporate NMP, cut into disks with a diameter of $14 \mathrm{~mm}$, and dried overnight at $45{ }^{\circ} \mathrm{C}$ under vacuum. The electrode disks had a sulfur loading between 1.7 and $2.9 \mathrm{mg} \mathrm{cm}^{-2}$ (see Table S1 in the Supplementary data for details on the average sulfur mass loading over the electrodes).

\subsection{Materials characterization}

X-ray diffraction (XRD) patterns of the S-C composite powders were collected in the $2 \theta$ range between $10^{\circ}$ and $70^{\circ}$ with a scan rate of $0.4^{\circ}$ $\mathrm{min}^{-1}$ and a step size of $0.01^{\circ}$, through a Rigaku SmartLab diffractometer using a $\mathrm{Cu}-\mathrm{K} \alpha$ source. The powders were spread on a glass sample holder for XRD. Phase identification was performed by comparing the experimental XRD patterns with the reference data of the Inorganic Crystal Structure Database (ICSD). Scanning electron microscopy (SEM) and energy dispersive X-ray spectroscopy (EDS) analyses of the powders were carried out by means of a Zeiss EVO MA10 employing a tungsten thermionic electron gun and an INCA X-ACT Oxford Instrument analyzer.

X-ray nano-CT imaging of the S-C materials was performed using a Zeiss Xradia 810 Ultra instrument (Carl Zeiss Inc.) equipped with a micro-focus rotating $\mathrm{Cr}$ anode with characteristic energy at $5.4 \mathrm{keV}$ (Cr$\mathrm{K} \alpha$, MicroMax-007HF, Rigaku) set at $35 \mathrm{kV}$ and $25 \mathrm{~mA}$. Samples for Xray nano-CT were prepared by securing the powder on stainless steel (SS) needles by epoxy [2,4,6-tris(dimethylaminomethyl)phenol, Devcon] with the aid of an optical microscope. The X-ray beam was focused onto the sample by a condenser lens in an elliptical capillary hosted inside a He-filled chamber (condenser chamber). A Fresnel zone plate inside a further He-filled chamber (optics chamber) focused the X-ray beam coming from the specimen onto a charge-coupled device (CCD) detector. An optional Au ring inside the optics chamber was used to achieve Zernike phase contrast by utilizing phase shifts across the incident X-ray beam. Thus, two different CT scans in absorption-contrast and Zernike phase-contrast modes [38], respectively, have been performed for each sample by recording radiographs (from 901 to 1201 projections, with exposure times from 10 to $16 \mathrm{~s}$ for the former mode and from 40 to $50 \mathrm{~s}$ for the latter mode) through $180^{\circ}$ in a field of view of 65 $\mu \mathrm{m}$, with a 2 voxel binning. The acquisition parameters led to a voxel size of ca. $126 \mathrm{~nm}$. Absorption-contrast and Zernike phase-contrast datasets were reconstructed by the Zeiss XMReconstructor software (Carl Zeiss Inc.) using a filtered back-projection algorithm, and then visualized and merged through the Avizo 2019.4 software (Visualization Sciences Group, FEI Company) [38]. The merged tomographic data were further processed by applying a non-local means filter, segmented, and imaged through the Avizo 2019.4 software (Visualization Sciences Group, FEI Company). Three domains with increasing X-ray attenuation were identified by employing grayscale thresholding [35,39] and watershed [40] methods, that is, (i) exterior, (ii) carbon, and (iii) sulfur.

$\mathrm{X}$-ray micro-CT imaging of the electrodes was carried out using a Zeiss Xradia 520 Versa instrument (Carl Zeiss Inc.) equipped with a polychromatic micro-focus source (tungsten target) set either at $80 \mathrm{kV}$ and $88 \mu \mathrm{A}$ or at $90 \mathrm{kV}$ and $89 \mu \mathrm{A}$. Samples with a size of about $1 \times 1 \mathrm{~mm}$ were cut from each electrode sheet and stuck to a SS dowel by epoxy [2,4,6-tris(dimethylaminomethyl)phenol, Devcon]. Tomographic scans were performed by taking 1601 projections through $360^{\circ}$ and acquiring images through a 40X objective lens with an X-ray exposure between 40 and $50 \mathrm{~s}$ and 1 voxel binning. Source-specimen and detector-specimen distances were set in the ranges from 12.0 to $15.0 \mathrm{~mm}$ and from 8.8 to $11.8 \mathrm{~mm}$, respectively. The experimental conditions were carefully tuned to ensure suitable $\mathrm{X}$-ray transmission values as well as a voxel size within the 192-198 nm range and a field of view within the 358-385 $\mu \mathrm{m}$ range, depending on the sample. Tomographic datasets were reconstructed by the Scout-and-Scan Control System Reconstructor software (Carl Zeiss Inc.) using a filtered back-projection algorithm, and then processed by applying a non-local means filter, segmented, visualized, and analyzed through the Avizo 2019.4 software (Visualization Sciences Group, FEI Company). Four domains with increasing X-ray attenuation were identified by employing grayscale thresholding [35,39] and watershed [40] methods: (i) exterior, (ii) carbon/binder, (iii) carbon-cloth fibers, and (iv) sulfur. Binary datasets were produced for the sulfur domain, processed by particle separation tools through the Avizo 2019.4 software (Visualization Sciences Group, FEI Company) and further analyzed by means of the ImageJ plugin XLib [41] and the Avizo 2019.4 software to calculate the discrete particle size distribution (PSD) and sphericity (shape factor) distribution according to equation (1):

$($ Sphericity $)=\pi^{1 / 3} \frac{(6 V)^{2 / 3}}{A}$

where $\mathrm{V}$ and $\mathrm{A}$ are the estimated volume and surface of the particles.

\subsection{Electrolyte preparation, cell assembly and electrochemical characterization}

1,3-Dioxolane (DOL, anhydrous, containing ca. $75 \mathrm{ppm}$ of butylated hydroxytoluene, i.e., BHT, as inhibitor, 99.8\%, Sigma-Aldrich) and 1,2dimethoxyethane (DME, anhydrous, inhibitor-free, 99.5\%, SigmaAldrich) were dried under molecular sieves ( $3 \AA$ A, rod, size $1 / 16$ in., Honeywell Fluka) until the water content was below 10 ppm according to a Karl Fischer titration (899 Coulometer, Metrohm). Lithium bis(trifluoromethanesulfonyl)imide (LiTFSI, 99.95\% trace metals basis, Sigma-Aldrich) and lithium nitrate $\left(\mathrm{LiNO}_{3}, 99.99 \%\right.$ trace metals basis, Sigma-Aldrich) were dried under vacuum at 110 and $80^{\circ} \mathrm{C}$, respectively, for 3 days. An electrolyte solution was prepared by dissolving LiTFSI and $\mathrm{LiNO}_{3}$ in a 1:1 (w:w) DOL:DME mixture in a concentration of either salts with respect to the solvent mass of $1 \mathrm{~mol} \mathrm{~kg}^{-1}$. CR2032 coin-cells (MTI Corp.) were assembled by stacking a lithium disk with a diameter of 14 $\mathrm{mm}$, a Celgard 2400 separator with a diameter of $16 \mathrm{~mm}$ soaked by $50 \mu \mathrm{l}$ of electrolyte solution, and the sulfur-carbon composite electrode (see Table S1 in the Supplementary data for details on the average sulfur mass loading over the electrodes and corresponding electrolyte/sulfur ratio in the cells). Electrolyte preparation and coin-cell assembly were carried out in an Ar-filled glovebox (MBraun, $\mathrm{O}_{2}$ and $\mathrm{H}_{2} \mathrm{O}$ content below $1 \mathrm{ppm})$.

The rate capability of the coin cells was tested by galvanostatic cycling at a current rate increasing every 5 cycles, that is, at $\mathrm{C} / 10, \mathrm{C} / 8$, $\mathrm{C} / 5, \mathrm{C} / 3, \mathrm{C} / 2,1 \mathrm{C}$ and $2 \mathrm{C}$, and decreasing back to the initial value $(\mathrm{C} / 10)$ at the 36 th cycle $\left(1 \mathrm{C}=1675 \mathrm{~mA} \mathrm{gs}^{-1}\right)$. The cycle life of the coin cells was evaluated by galvanostatic measurements at a current rate of $\mathrm{C} / 3(1 \mathrm{C}=$ $1675 \mathrm{~mA} \mathrm{gS}^{-1}$ ). The cycling tests were carried out within voltage ranges of $1.9-2.8 \mathrm{~V}$ from $\mathrm{C} / 10$ to $\mathrm{C} / 2$ and of $1.8-2.8 \mathrm{~V}$ from $1 \mathrm{C}$ to $2 \mathrm{C}$, by using a MACCOR series 4000 battery test system.

All the measurements were carried out at room temperature $\left(25^{\circ} \mathrm{C}\right)$.

\section{Results and discussion}

As mentioned in the introduction, viable approaches to achieve composite cathodes for Li-S batteries include simple pathways according to which elemental sulfur is thoroughly mixed with carbon [25], such as those adopted herein by directly employing molten sulfur (S@SPC-MP and S@MWCNTs-MP composites) or by benefitting from an alcohol dispersion as the synthesis precursor (S@SPC-SAP and S@MWCNTs-SAP composites). In this regard, the microstructure of the positive electrode, depending on both the carbon nature and the synthesis condition, may certainly affect the electrochemical characteristics [32,42], although a careful optimization of the various cell components is crucial for favoring a reversible sulfur conversion over long cycling $[9,16,18]$. The $\mathrm{XRD}$ patterns of the four composites reported in Fig. 1 reveal the expected structure of the orthorhombic sulfur (ICSD \# 63082) for all the materials (see experimental section for acronyms) and a small peak at 


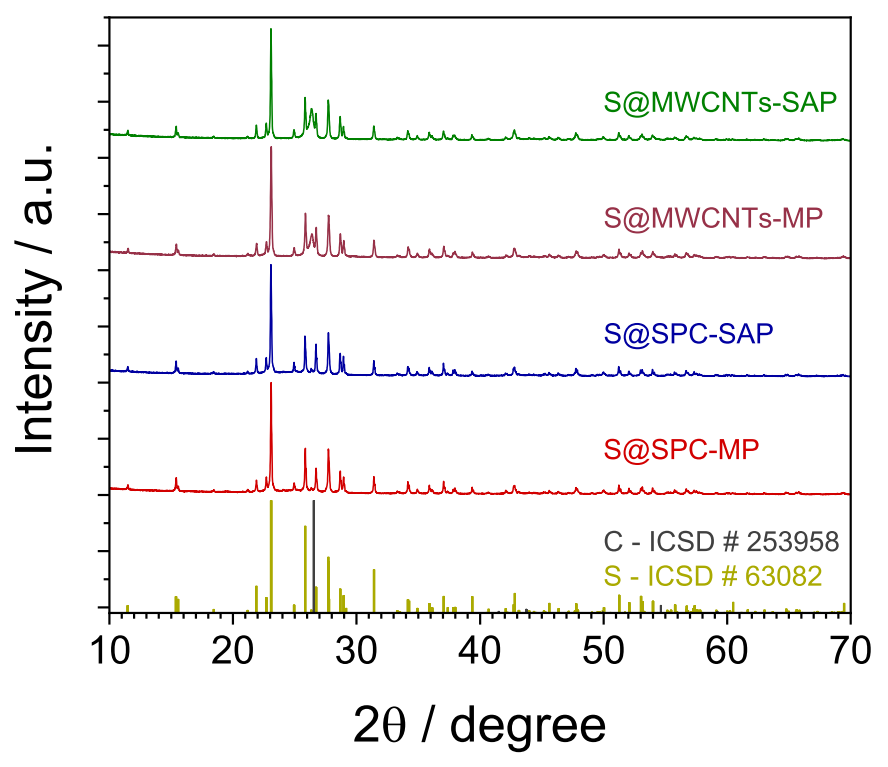

Fig. 1. XRD patterns of the S-C powders recorded using a $\mathrm{Cu}-\mathrm{K} \alpha$ source (scan rate of $0.4^{\circ} \mathrm{min}^{-1}$, step size of $0.01^{\circ}$ ), with reference reflections of hexagonal graphite (ICSD \# 253958, space group $P 6_{3} / m m c$, No. 194) and orthorhombic sulfur (ICSD \# 63082, space group Fddd, No. 70).

about $26^{\circ}(2 \theta)$ for both S@MWCNTs-MP and S@MWCNTs-SAP due to the graphitic character of MWCNTs [25,43,44]. On the other hand, S@SPC-MP and S@SPC-SAP do not show significant crystalline phases besides sulfur due to the predominantly amorphous nature of SPC. The full width at half maximum (FWHM) of the sulfur phase indicates relatively large crystal domains for all the powders, thereby suggesting the possible formation of heterogeneous mixtures of carbon and micrometric sulfur particles, rather than S-embedded into the carbons. It is worth noting that electrode materials with similar structure, however with lower sulfur content [25] or adopting a different preparation technique [32], have already shown suitable features in Li-S batteries as well as appealing characteristics in terms of the relative simplicity and possible scalability of the synthesis pathway.

A detailed morphological analysis combining SEM, EDS and X-ray nano-CT (see Figs. 2 and 3) corroborates the hypothesis drawn from $\mathrm{XRD}$, showing that all the composites consist of discrete, irregular sulfur particles with a size ranging from a few micrometers to about $50 \mu \mathrm{m}$ surrounded by carbon. Despite the similarities, the materials reveal different morphological features depending on both the carbon nature and the preparation route. Accordingly, the SEM images at low magnification (Fig. 2a, e, i, and $\mathrm{m}$ ) indicate that the MP ensures a better dispersion of the electrode components and smaller sulfur particles than the SAP, as indeed evidenced by EDS mapping (Fig. $2 b-c, f-g, j-k$, and $\mathrm{n}-\mathrm{O}$ ), while a detail of samples at high magnification (Fig. $2 \mathrm{~d}, \mathrm{~h}, \mathrm{l}$, and p) clearly shows micrometric aggregates of C nanoparticles for S@SPC-MP and S@SPC-SAP and randomly oriented C fibers with nanometric width and micrometric length for S@MWCNTs-MP and S@MWCNTs-SAP.

Even though SEM-EDS may be a powerful tool to investigate the composite morphology, nanoscale imaging of the bulk by X-ray CT advantageously provides a $3 \mathrm{D}$ reconstruction of sulfur-carbon agglomerates in a field of view of about $65 \mu \mathrm{m}$, thereby allowing us to further appreciate the effect of the carbon and synthesis procedure on the material microstructure. High-resolution datasets, gathering complementary information on both the X-ray attenuation and the submicrometric features due to edge enhancement, have been obtained by combining tomographic reconstructions of scans in absorption-contrast and Zernike phase-contrast modes, respectively [38]. Fig. S1 in the Supplementary data shows cross-sectional slices extracted in the $\mathrm{xz}$ plane (where $\mathrm{z}$ is the rotation axis orthogonal to the incident beam). The absorption-contrast imaging (Figs. S1a, c, e, and g) reflects the different X-ray transmission through sulfur (highly attenuating) and carbon (lowly attenuating), which allows us a straightforward phase identification, while the Zernike phase-contrast image (Figs. S1b, d, f, and h) reveals the diverse morphology of SPC and MWCNTs. Thus, the carbon phase in S@SPC-MP and S@SPC-SAP is mostly arranged according to a homogenous texture of nanoparticles (see Figs. S1b and d), while S@MWCNTs-MP and S@MWCNTs-SAP exhibit well-defined features attributed the nanotubes (see Figs. S1f and h). Therefore, the corresponding images produced by merging phase and absorption contrast data, shown in Fig. 3a, b, c, and $\mathrm{d}$, suggest that the MP may give rise to a lower degree of sulfur aggregation than the SAP (compare panels a and $c$ with panels $b$ and $d$, respectively). Interestingly, the sulfur agglomerates contain micro- and nanopores in S@SPC-MP and S@MWCNTs-MP; in contrast, S@SPC-SAP and S@MWCNTs-SAP are characterized by large sulfur particles with low porosity and relatively high attenuation of the incident beam. Further processing by image segmentation according to grayscale threshold [35,39] and watershed [40] methods has been carried out to get a volume rendering of the specimens (see Fig. 3e, f, g, and h). The images illustrate the 3D distribution at the nanoscale (voxel size of 126 $\mathrm{nm}$ ) of the sulfur particles (yellow phase) surrounded by carbon domains (gray phase), thus providing a visual representation supporting the above reported observations.

As already mentioned, the electrode substrate [16] and the microstructure of the deposited electrode film [18] may play a crucial role in determining optimal performances besides the structural and morphological features of the sulfur-based material. On the other hand, the sulfur particle size and shape distributions, as well as the carbon nature, might reasonably affect key characteristics of the electrode coating. Therefore, we have investigated by X-ray micro-CT the positive electrodes supported on a carbon-cloth current collector, which has been widely investigated elsewhere as a promising alternative to conventional aluminum, benefiting from suitable porosity and surface properties [15]. Compared to the tomographic surveys at the nanoscale in Fig. 3, X-ray micro-CT has a lower resolution but it ensures a much larger field of view (between 358 and $385 \mu \mathrm{m}$ in our experimental conditions), which may allow us to build the $3 \mathrm{D}$ reconstruction of a more representative volume for a quantitative analysis of the sulfur phase. Moreover, the carbon cloth is a particularly suitable support for tomography due to its lower X-ray attenuation with respect to aluminum, which enables an unambiguous sulfur detection and facilitates the segmentation by thresholding [36]. Fig. S2 in the Supplementary data reports the reconstructed electrode volume renderings, where the grayscale reflects the beam attenuation. All the samples consist of a composite film with relatively high density including sulfur, polymeric binder, and conductive carbon additive deposited on a low-density cloth. Additional features are revealed by Fig. 4, showing the reconstructed images of the electrodes in terms of a cross-sectional slice extracted in the $\mathrm{xz}$ plane (where $\mathrm{z}$ is the rotation axis orthogonal to the X-ray beam and to the electrode plane, panels a, $\mathrm{d}, \mathrm{g}$, and $\mathrm{j}$ ) and represented by a grayscale indicating the X-ray attenuation, along with the corresponding segmented slice (panels b, e, h, and k) and volume rendering (panels c, f, $\mathrm{i}$, and 1) [35]. The left-hand side panels (Fig. 4a, d, g, and j) reveal (i) highly attenuating sulfur particles with size and shape distributions apparently depending on both the carbon nature in the S-C composite (SPC and MWCNTs) and the synthesis procedure (MP and SAP), (ii) the moderately attenuating cloth fibers, and (iii) a lowly attenuating carbon/binder domain. Furthermore, X-ray CT clearly shows the carbon coating of the cloth, having similar attenuation to the carbon/binder domain, which is mostly located between the electrode film and the fibers. The corresponding segmented slices (Fig. 4b, e, h, and k) depict (i) the sulfur particles in yellow, (ii) the carbon fibers in light gray, (iii) the carbon/binder phases in dark gray, and (iv) the exterior/pores in black, whereas the right-hand side panels (Fig. 4c, f, i, and l) display the related $3 \mathrm{D}$ renderings using the same color map except for the exterior/pore which is not considered. Notably, Fig. 4 shows that the S@SPC-MP 


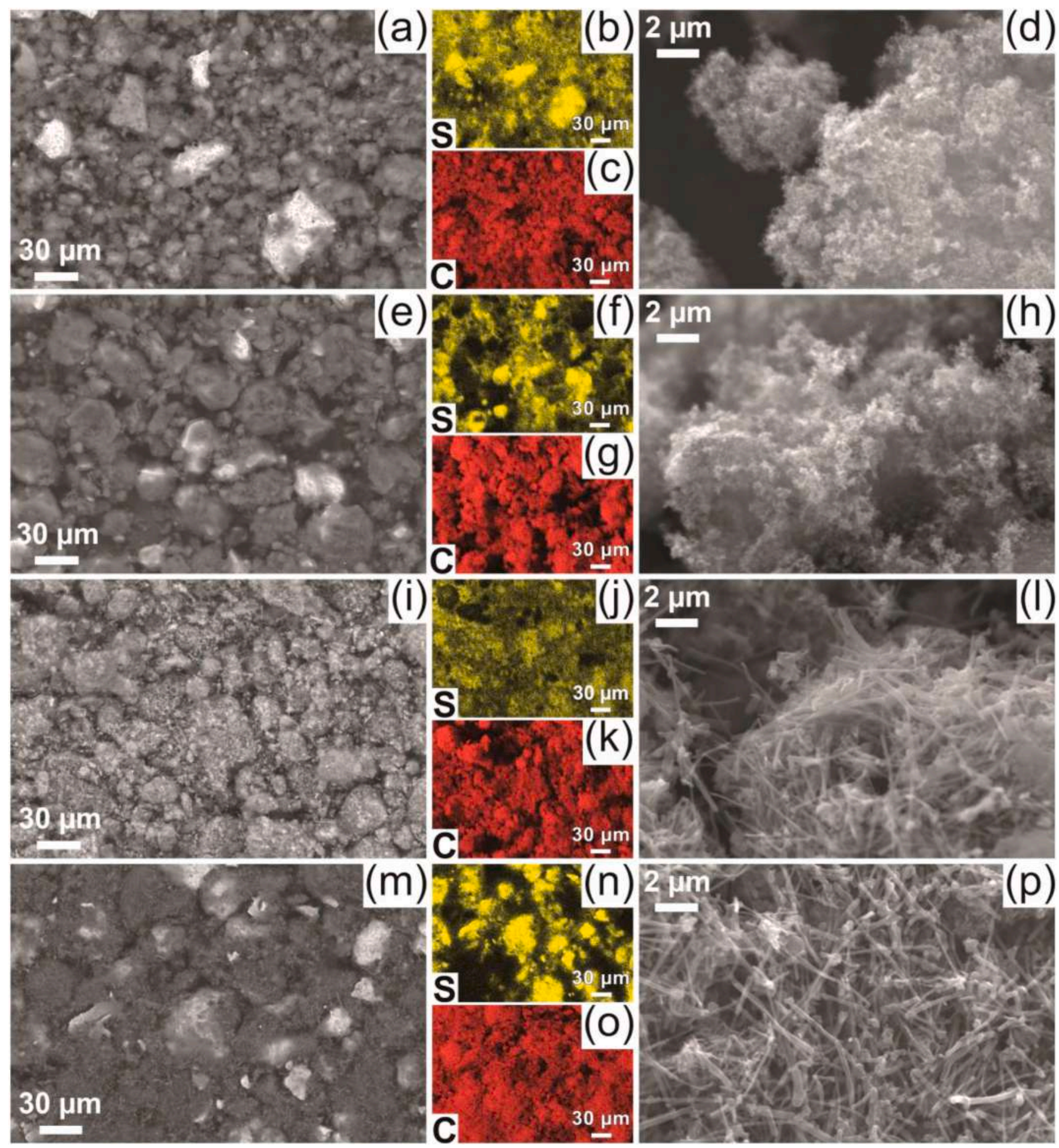

Fig. 2. Morphological analysis of (a-d) S@SPC-MP, (e-h) S@SPC-SAP, (i-1) S@MWCNTs-MP, and (m-p) S@MWCNTs-SAP. In detail: (a and d, e and h, i and 1, m and $\mathbf{p})$ SEM images at two different magnifications in (a, e, i, $\mathbf{m})$ backscattered and $(\mathbf{d}, \mathbf{h}, \mathbf{1}, \mathbf{p})$ secondary electron modes (accelerating voltage: $15 \mathrm{kV})$; (b and $\mathbf{c}, \mathbf{f}$ and $\mathbf{g}, \mathbf{j}$ and $\mathbf{k}, \mathbf{n}$ and $\mathbf{o})$ EDS maps of $(\mathbf{b}, \mathbf{f}, \mathbf{j}, \mathbf{n}) \mathrm{S}$ and $(\mathbf{c}, \mathbf{g}, \mathbf{k}, \mathbf{o}) \mathrm{C}$ on the samples.

electrode is mostly formed by sulfur particles having a size of a few micrometers, besides large agglomerates approaching $50 \mu \mathrm{m}$ (see panels a-c), while the other samples mainly contain sulfur domains of approximately $10-50 \mu \mathrm{m}$ (see panels $\mathrm{d}-1$ ). Therefore, the carbon nature remarkably affects the electrode microstructure when using the MP (compare Fig. 4a-c with Fig. 4g-i) but has only a minor influence on the sulfur particle size when SAP is employed (compare Fig. 4d-f with Fig. $4 \mathrm{j}-1$ ). Moreover, X-ray micro-CT suggests that the MP might favor the mixing between the electrode components with respect to the SAP (compare Fig. 4a-c and g-i with Fig. 4d-f and Fig. 4j-1, respectively).

A quantitative evaluation of the effect of carbon additive and synthesis pathway may be achieved through a comparison of the sulfur PSD in the various samples, which has been calculated herein by processing binary 3D images reconstructed from the micro-CT datasets of Fig. 4. The particle size, quantified in Fig. 5a, c, e, and $g$ by the radius of related spheres with equivalent volume [40], reveals that the MP actually 


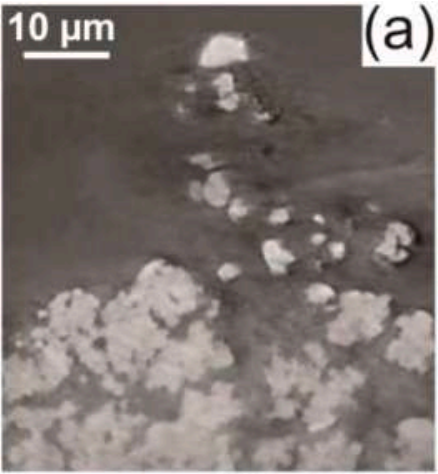

(e)
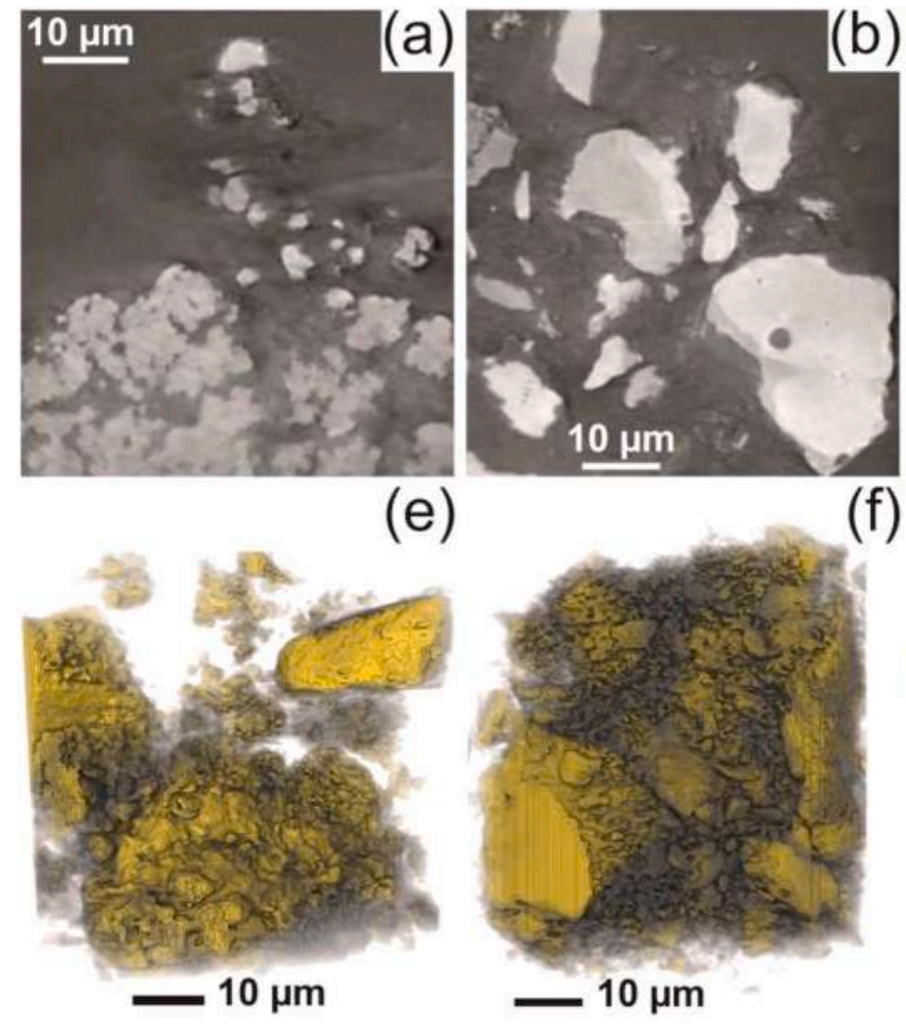

(f)

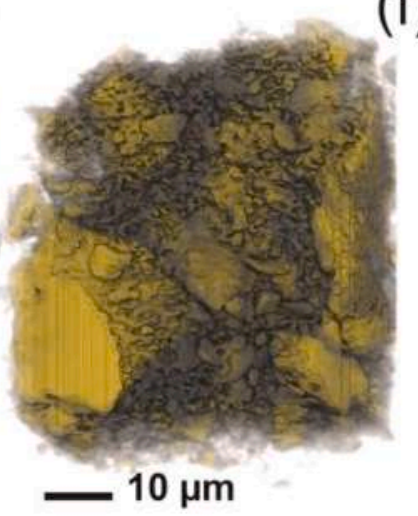

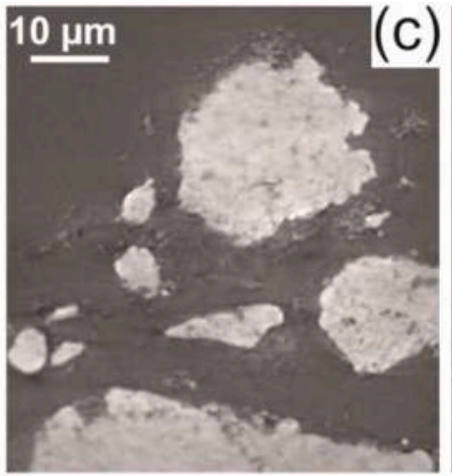

(g)

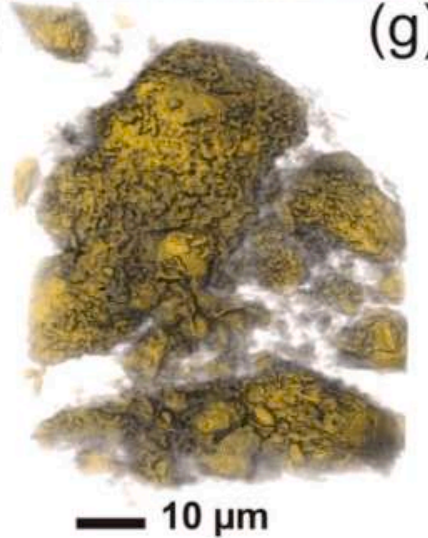

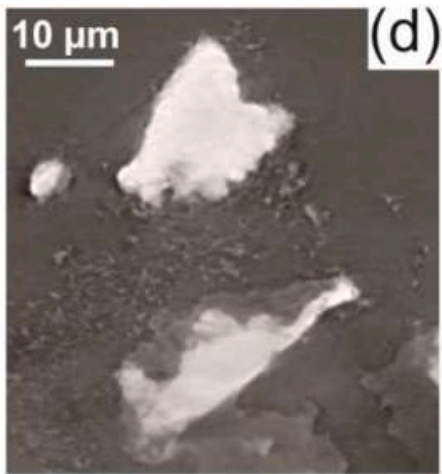

(h)

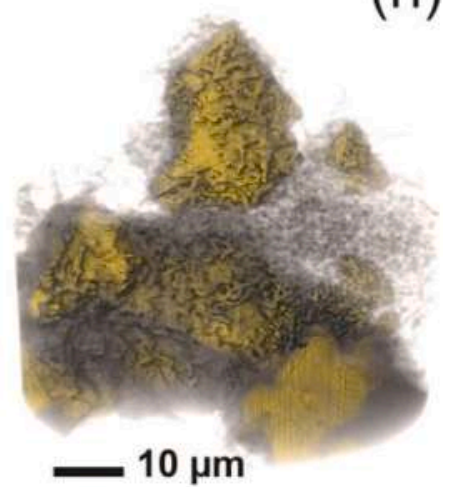

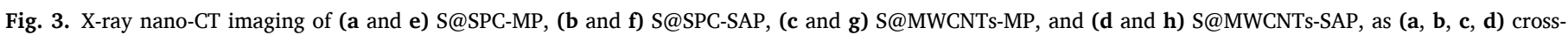

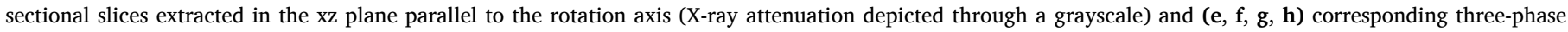

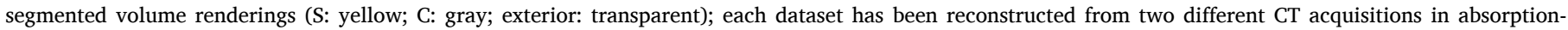

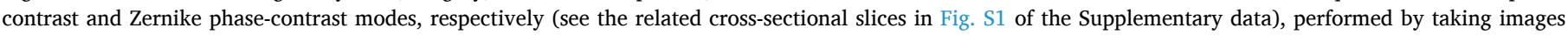

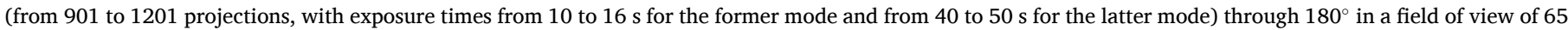

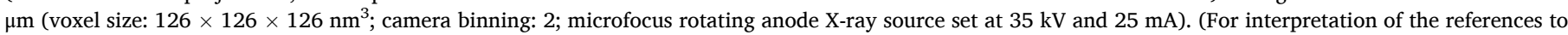
color in this figure legend, the reader is referred to the Web version of this article.)

ensures smaller sulfur domains than the SAP as previously supposed (compare panels a and e with panels $\mathrm{c}$ and $\mathrm{g}$, respectively). S@SMWCNTs-MP (Fig. 5e) exhibits a narrower distribution than S@SPC-MP (Fig. 5a), with about the 90\% of the phase being dispersed in particles of equivalent radius below $13 \mu \mathrm{m}$, although a large number of sulfur domains in the latter electrode (about 50\%) have an equivalent radius smaller than $7 \mu \mathrm{m}$, whereas S@SPC-SAP (Fig. 5c) and S@SMWCNTs-SAP (Fig. 5g) have similar distributions and significantly larger average size. A further visual representation of the PSD by volume rendering in the $\mathrm{xy}$ and $\mathrm{xz}$ planes (where $\mathrm{z}$ is the vertical rotation axis of the sample relative to the X-ray beam) clearly shows the difference between the specimens (see Fig. S3 in the Supplementary data). A shape factor analysis quantifying the deviation from the spherical shape according to equation (1) (see the experimental section for further details) indicates for S@SPC-MP (Fig. 5b) a relatively wide distribution with small average values compared to the other samples (Fig. $5 \mathrm{~d}$, f, and h).

The above observations might be attributed to a high sulfur nucleation rate by crystallization using the MP, which can lead to small sulfur particles and large domains with low sphericity perhaps formed by coalescence, particularly enabled by the SPC due to its sub-micrometric or nanometric morphology [45]. On the other hand, the similar microstructure of S@SPC-SAP and S@SMWCNTs-SAP might imply that the SAP, which includes thermal treatment of pelletized precursors obtained from the alcohol dispersions, decreases the number of sulfur crystallization centers, mitigates the specific S-C interaction, slows down the nucleation, and favors the particle growth rate (see the experimental section for the synthetic procedures). A detailed visual overview of the electrodes features discussed above is given by the supplementary animations obtained by CT tomography (Movies S1, S2, S3 and S4 for
S@SPC-MP, S@SPC-SAP, S@MWCNTs-MP and S@SMWCNTs-SAP, respectively).

Supplementary video related to this article can be found at https:// doi.org/10.1016/j.jpowsour.2020.228424.

The sulfur particle size and the carbon morphology generally have a remarkable effect on the electrochemical reaction kinetics in $\mathrm{Li} / \mathrm{S}$ batteries [28,32], as indeed demonstrated for the four composites studied herein. Fig. 6 reports the responses of rate capability tests in lithium cells of the S-C electrodes in terms of voltage profiles (panels a-d) and cycling behavior (panel e) at current rates increasing from $\mathrm{C} / 10$ to $2 \mathrm{C}(1 \mathrm{C}=$ $1675 \mathrm{~mA} \mathrm{~g}_{\mathrm{S}}^{-1}$ ). Table S2 in the Supplementary data reports the related specific capacity values considering the $S$ mass as well as that of the inactive components in the electrode film. All the cells exhibit the typical plateaus at about 2.3 and $2.1 \mathrm{~V}$ during discharge, and at about 2.4 and $2.2 \mathrm{~V}$ during charge (see Fig. 6a-d), reflecting the well-known conversion of elemental sulfur to soluble polysulfides $\left(\mathrm{Li}_{2} \mathrm{~S}_{x}\right.$, where 4 $\leq x \leq 8$ ), as well as to solid $\mathrm{Li}_{2} \mathrm{~S}_{2}$ and possibly $\mathrm{Li}_{2} \mathrm{~S}$ [6]. The voltage curves reveal a high reversibility and the effective mitigation of the polysulfide shuttling by $\mathrm{LiNO}_{3}$ [12], although the extent of the expected increase in cell polarization by raising the current may suggest faster kinetics for S@SPC-MP and S@MWCNTs-MP when compared to the corresponding materials prepared by SAP, i.e., S@SPC-SAP and S@MWCNTs-SAP. Indeed, S@SPC-MP and S@MWCNTs-MP ensure a suitable process up to $1 \mathrm{C}$ and $\mathrm{C} / 2$ rates, while the increasing overvoltage of S@SPC-SAP and S@MWCNTs-SAP hinders the second plateau above $\mathrm{C} / 2$ and $\mathrm{C} / 3$ rates, respectively (compare Fig. $6 \mathrm{a}$ and $\mathrm{c}$ with Fig. $6 \mathrm{~b}$ and d). As for the effect of carbon, the SPC-based electrodes have enhanced rate capability, a higher capacity, and a lower cell polarization than the MWCNTs-containing counterparts (compare Fig. 6a and b with Fig. 6c 


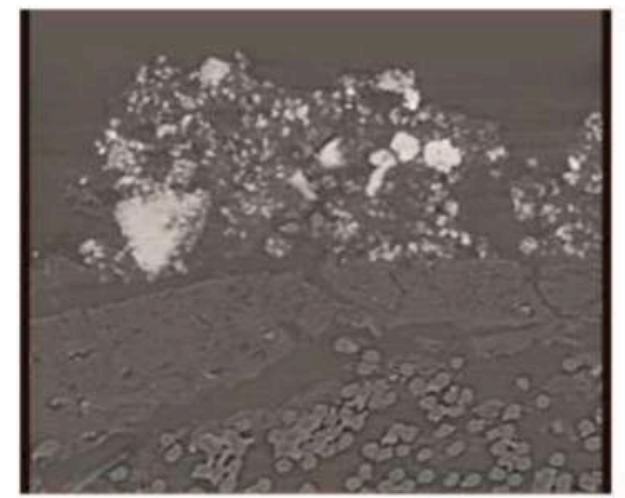

(a)

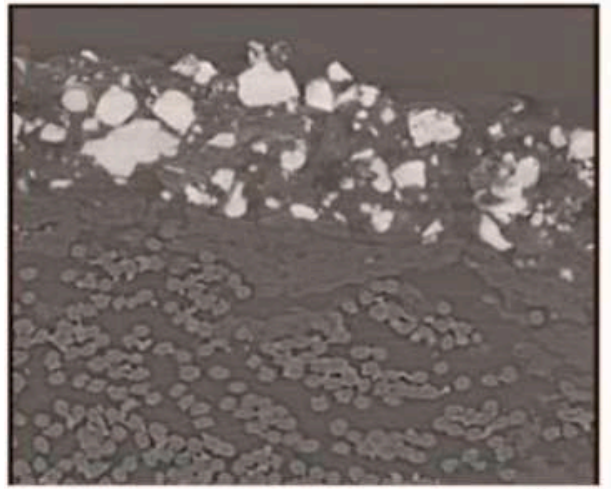

$100 \mu \mathrm{m}$

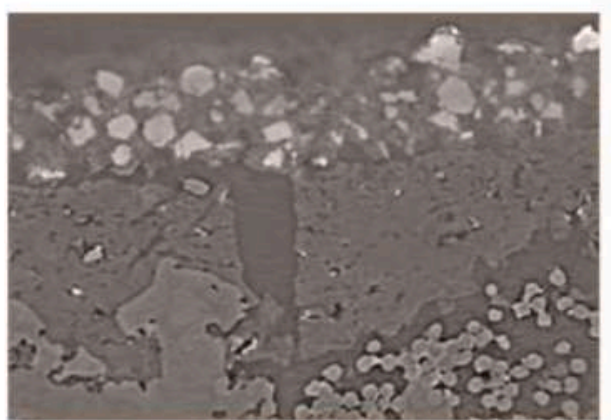

$100 \mu \mathrm{m}$

(g)

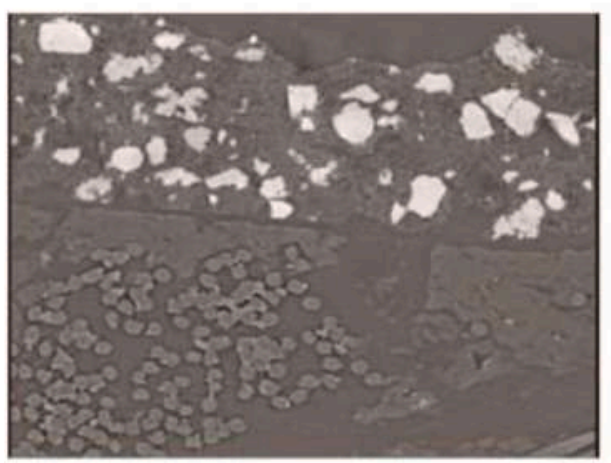

$100 \mu \mathrm{m}$

(d)

(j)

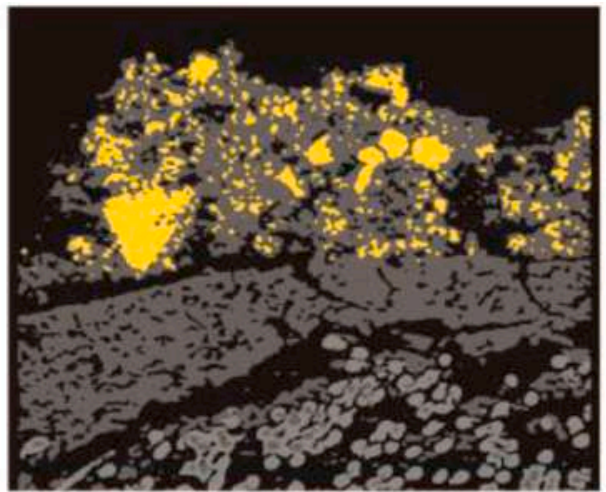

(b)
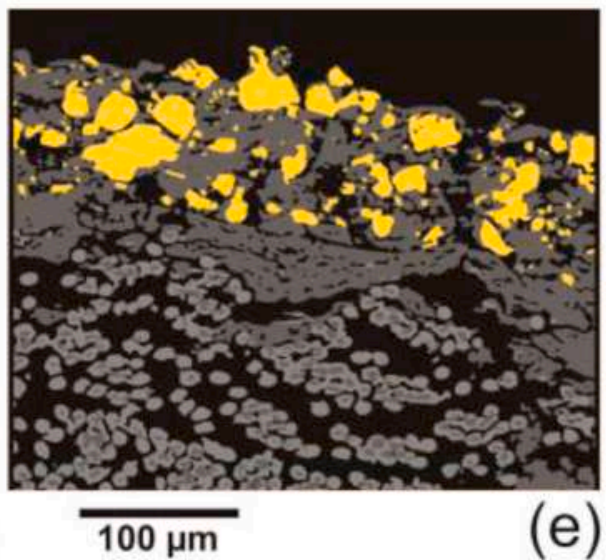

(e)

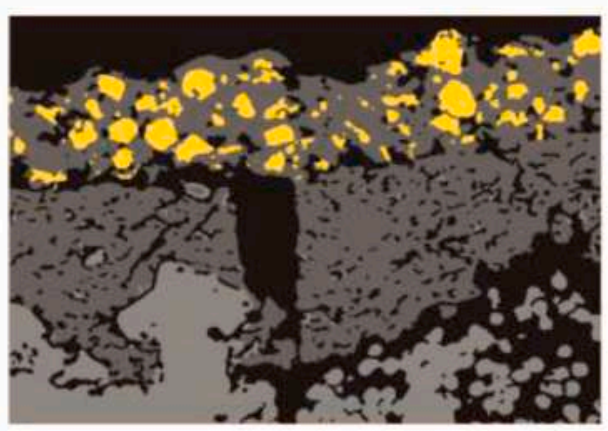

(h)
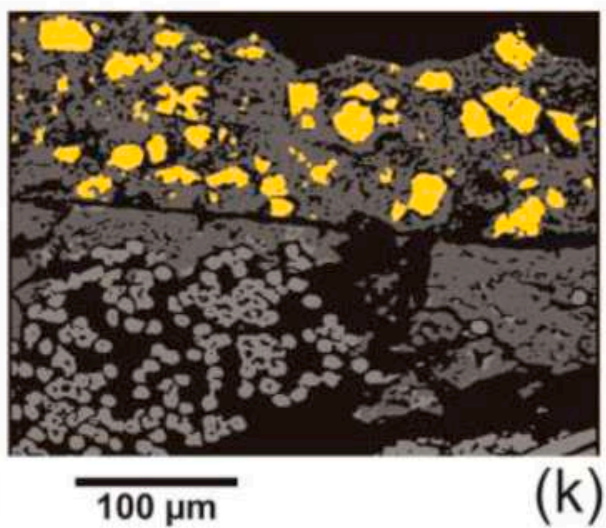

(k)
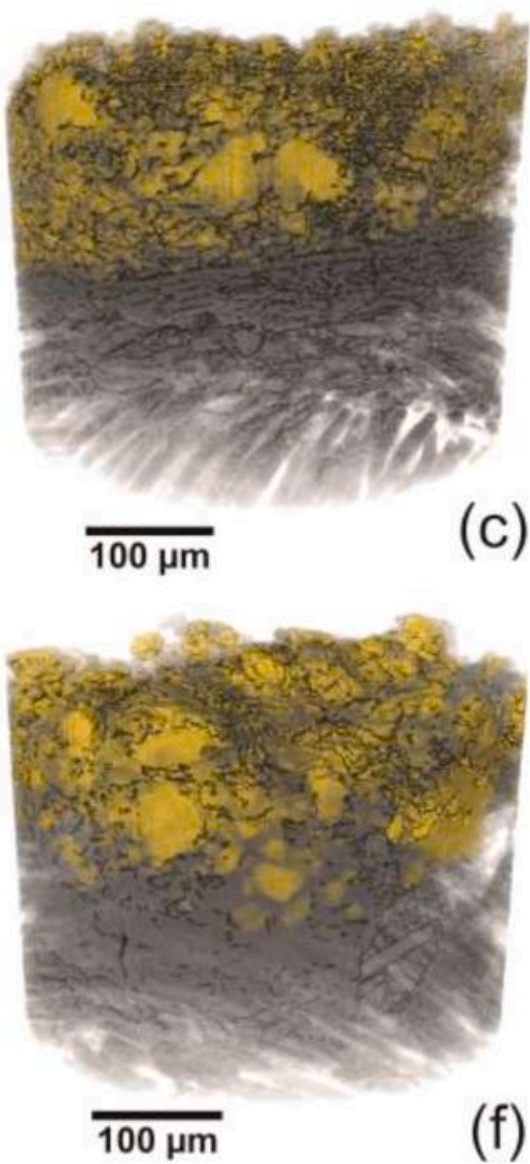

(f)

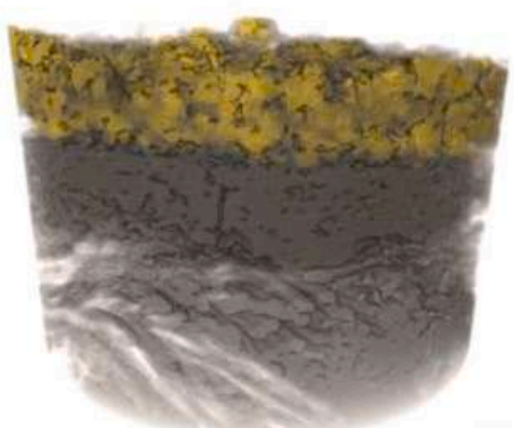

(i)

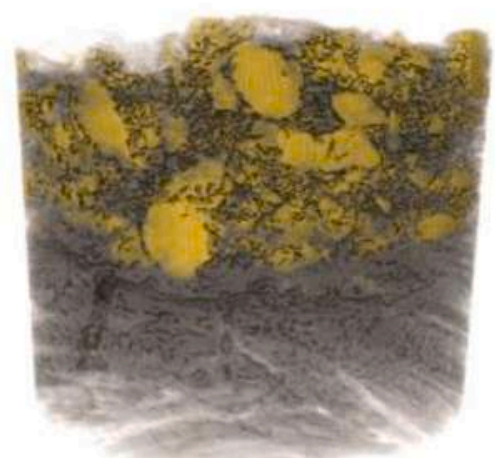

$\overline{100 \mu \mathrm{m}}$ 


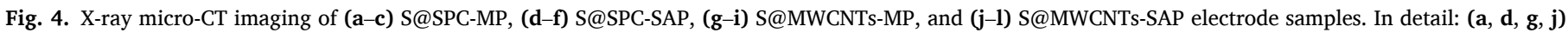

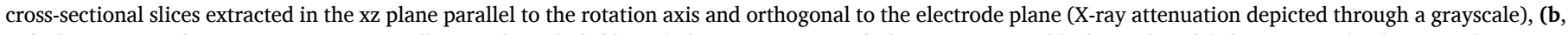

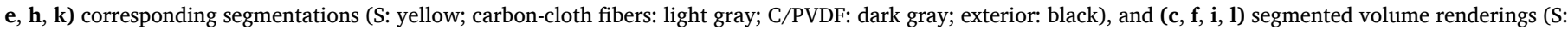

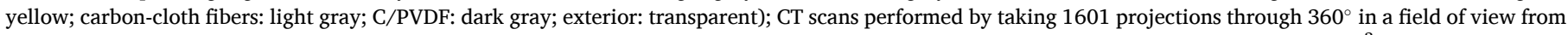

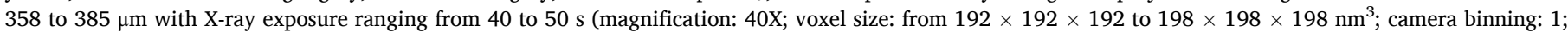

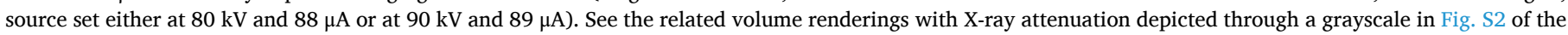
Supplementary data. (For interpretation of the references to color in this figure legend, the reader is referred to the Web version of this article.)

and d, respectively). Accordingly, S@SPC-MP demonstrates the highest rate capability among the investigated configurations, with a reversible capacity ranging from about $1510 \mathrm{mAh} \mathrm{g}_{S}^{-1}$ at C/10 to about $1160 \mathrm{mAh}$ $\mathrm{gS}_{\mathrm{S}}^{-1}$ at $1 \mathrm{C}$, whereas S@MWCNTs-SAP delivers the lowest values, that is, ca. $1180 \mathrm{mAh} \mathrm{gS}^{-1}$ at C/10 and ca. $1040 \mathrm{mAh} \mathrm{g}^{-1}$ at C/3 $(1 \mathrm{C}=1675 \mathrm{mAh}$ $\mathrm{gs}^{-1}$; see Fig. 6e). Besides, S@SPC-SAP exhibits values as high as 1560 and $1510 \mathrm{mAh} \mathrm{gS}^{-1}$ at $\mathrm{C} / 10$ and $\mathrm{C} / 8$ but suffers from a more pronounced capacity decrease compared to S@SPC-MP as the rate further increases, while S@MWCNTs-MP ensures a capacity ranging from about $1340 \mathrm{mAh}$ $\mathrm{g}_{\mathrm{S}}^{-1}$ to about $1110 \mathrm{mAh} \mathrm{g}_{\mathrm{S}}^{-1}$ within $\mathrm{C} / 10$ and $\mathrm{C} / 2$ (see Fig. 6e). On the other hand, all the cells recover the initial capacity when the C-rate reverts to $\mathrm{C} / 10$ at the 36 th cycle. Therefore, a significant correlation between the rate performance and the sulfur PSD as determined by X-ray CT (see Fig. 5) is observed. Notably, the MP can effectually lead to smaller sulfur particles thereby possibly facilitating the $\mathrm{Li} / \mathrm{S}$ conversion at high current [46], and the nanometric morphology of SPC can further enhance the cell performance in terms of both reversible capacity and reaction kinetics. Furthermore, it is worth noticing that all the electrode formulations exhibit a satisfactory capacity ranging from 1030 to 1330 $\mathrm{mAh} \mathrm{gs}_{\mathrm{s}}^{-1}$ at the $\mathrm{C} / 3$ rate.

The cells have been tested at a constant current of $\mathrm{C} / 3$ over 150 cycles to evaluate possible effects of the electrode morphology on the capacity retention and the coulombic efficiency. Fig. 7 shows the corresponding voltage curves (panels a-d) along with the capacity and efficiency trends (panel e), whilst Table S3 in the Supplementary data displays the relevant specific capacity values considering the $\mathrm{S}$ mass as well as that of the inactive components in the electrode film. As already observed in previous works focusing on the electrochemistry of similar S-C composites [32], all the cells display an increase in reversible capacity after the first discharge reflecting an electrochemical activation promoted by the formation of a suitable electrode/electrolyte interphase [47], and a subsequent response partially in agreement with Fig. 6. Thus, the voltage profiles (Fig. 7a-d) reveal comparable overvoltage values, reversible capacities strongly depending on the carbon nature, and a capacity decay likely influenced by the synthesis procedure. In detail, the SPC ensures a higher reversible capacity than the MWCNTs as also shown in Fig. 6 and discussed above, that is, ca. $1470 \mathrm{mAh} \mathrm{gs}^{-1}$ compared to ca. $1060 \mathrm{mAh} \mathrm{gS}_{\mathrm{S}}^{-1}$, whereas the SAP has beneficial effects on the capacity retention with respect to the MP (see Fig. 7e). These observations suggest that large sulfur particles may mitigate the active material loss during cycling, in spite of adverse effect on the current capability [46], while carbon nanoparticles may promote the electrochemical conversion of the various polysulfides [24]. Indeed, S@SPC-MP suffers from a capacity fading to about $60 \%$ of the initial value after 150 cycles, although it has shown the best rate performance in Fig. 6 benefiting from the relatively small sulfur particles size (see Figs. 4 and 5) [46], while the large domains of electroactive material in S@SPC-SAP improve the retention to about 64\%. A similar trend is observed for S@MWCNTs-MP and S@MWCNTs-SAP, which deliver at the end of the test about 62 and $69 \%$ of the initial capacity, respectively (see Fig. 7e). The figure also provides evidence that composite electrodes consisting of micrometric sulfur particles and carbons of various morphologies prepared according to relatively simple pathways may ensure a promising cycling behavior at a C/3 rate $[25,42,47]$, with a coulombic efficiency above $98.8 \%$ indicating highly reversible conversion processes (see the right y-axis of Fig. 7e).

Notably, galvanostatic cycling in lithium cells leads to remarkable microstructural reorganizations in the sulfur cathode, as demonstrated in recent works [36]. In this regard, X-ray CT analyses of the positive electrode supported by XRD, SEM-EDS, and electrochemical data have shown that polysulfide dissolution in the electrolyte upon discharge and subsequent sulfur precipitation upon charge involve net migration of the active species towards the bulk of porous current collectors and close to electron-conducting centers [48]. Such rearrangements yield a gradual cathode amorphization accompanied by a decrease in sulfur particle size and sphericity factor, thus leading to a remarkable drop of the electrode/electrolyte interphase resistance along with a reaction potential shift [48]. These findings have evidenced a crucial role played by the morphology of the current collector at the positive side as well as by suitable sites for sulfur electrodeposition in the cathode, suggesting possible electrode-engineering strategies to enhance the conversion reaction. Instead, in this work we have taken into consideration the role of the pristine sulfur electrode morphology on the electrochemical performance in lithium cells rather than the morphological evolution of the cathode during cycling. The initial electrode microstructure appears in fact a key aspect for promoting optimized Li-S cell operation. Indeed, this study suggests that pristine sulfur distribution achieved by the different carbons and synthesis routes influences the sulfur nucleation sites, the electrode kinetics and electrodeposition upon the first cycle, which in turn affect the cell response during the whole cycling process.

In summary, we show herein that electrodes using the same carbon additive with different sulfur particle size distribution in pristine condition have different response in terms of specific capacity, rate capability, and cycling stability. Certainly, a full elucidation of this phenomenon might require further in situ and/or operando X-ray CT analyses of cathodes of various chemical nature and morphology to track their evolution during cycling, although ad hoc cell geometries usually employed in these studies appear to be not suitable for a comparison of performance between different materials due to the use of small electrode samples and high $\mathrm{E} / \mathrm{S}$ ratios as compared to the typical coin-cell configuration. In this regard, X-ray 3D imaging of a composite cathode as a function of state of charge has revealed significant morphological changes occurring in the sulfur phase, while the carbon/ binder domain was relatively stable during discharging and subsequent charging [34]. In particular, elemental sulfur has been reported to grow preferentially along cracks within the carbon/binder framework as well as close to the electrode/separator interface. Based on these considerations, our observations on the effect of morphology suggest that pristine sulfur distribution influences the microstructure of the carbon/binder framework, the sulfur nucleation sites and the kinetics of sulfur electrodeposition and, therefore, the cycling response of the cell.

\section{Conclusions}

Straightforward preparation routes of S-C composites for lithium batteries are presented herein, which involved mixing of commercial carbons, i.e., super P carbon black (SPC) and multiwalled carbon nanotubes (MWCNTs), with sulfur (70 wt\%) by direct melting or by exploiting an alcohol dispersion route. Significant insights into the effects of the synthesis pathway and the carbon nature on the cathode microstructure, and of the latter on the electrochemical performances in lithium cell, were achieved by complementary combination of XRD, SEM, and X-ray imaging at the nano- and microscale with galvanostatic cycling measurements across a wide current range. The composite cathodes consisted of heterogeneous dispersions of micrometric, crystalline sulfur particles surrounded by either SPC or MWCNTs and 

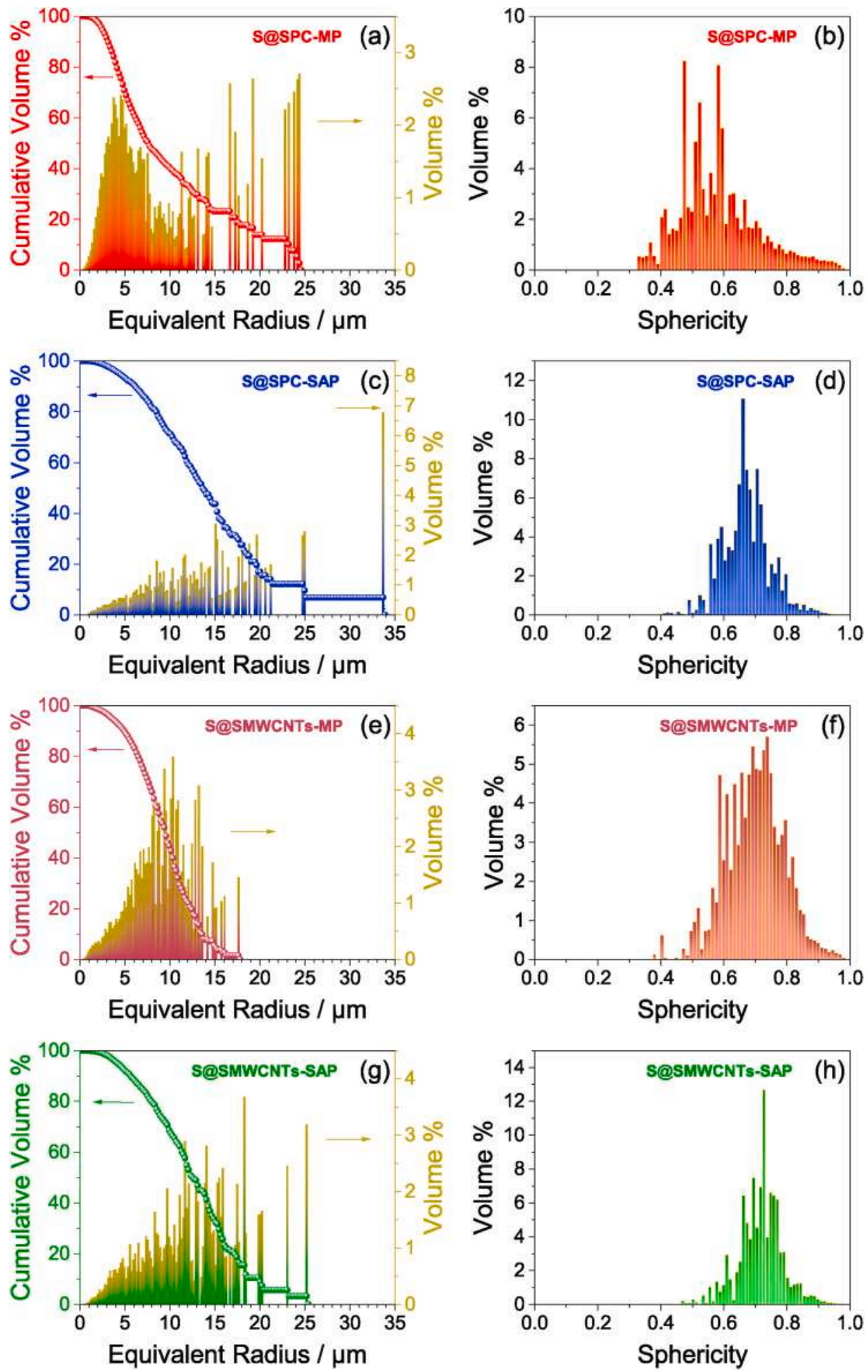

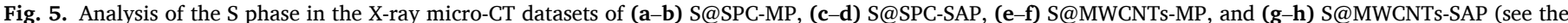

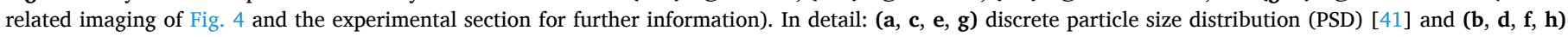
sphericity (shape factor) distribution. See the related renderings showing the PSD in the S phase in Fig. S3 of the Supplementary data.

embedded into the electrode film. Quantitative morphological analyses on the cathodes revealed that both the preparation pathway and the carbon source may efficiently control the sulfur particle size, thereby allowing a fine tuning of the electrode microstructure suitable to achieve an optimal battery performance in diverse testing conditions. Thus, our results suggested that small sulfur particles may enhance the rate capability but may adversely affect the capacity retention upon cycling by accelerating the active material loss. In this regard, sulfur melting and subsequent crystallization via quenching at room temperature (MP) led to smaller sulfur domains than the dispersion in an alcohol suspension followed by heating (SAP). SPC nanoparticles possibly promoted the nucleation of solid sulfur from the molten phase, ultimately 

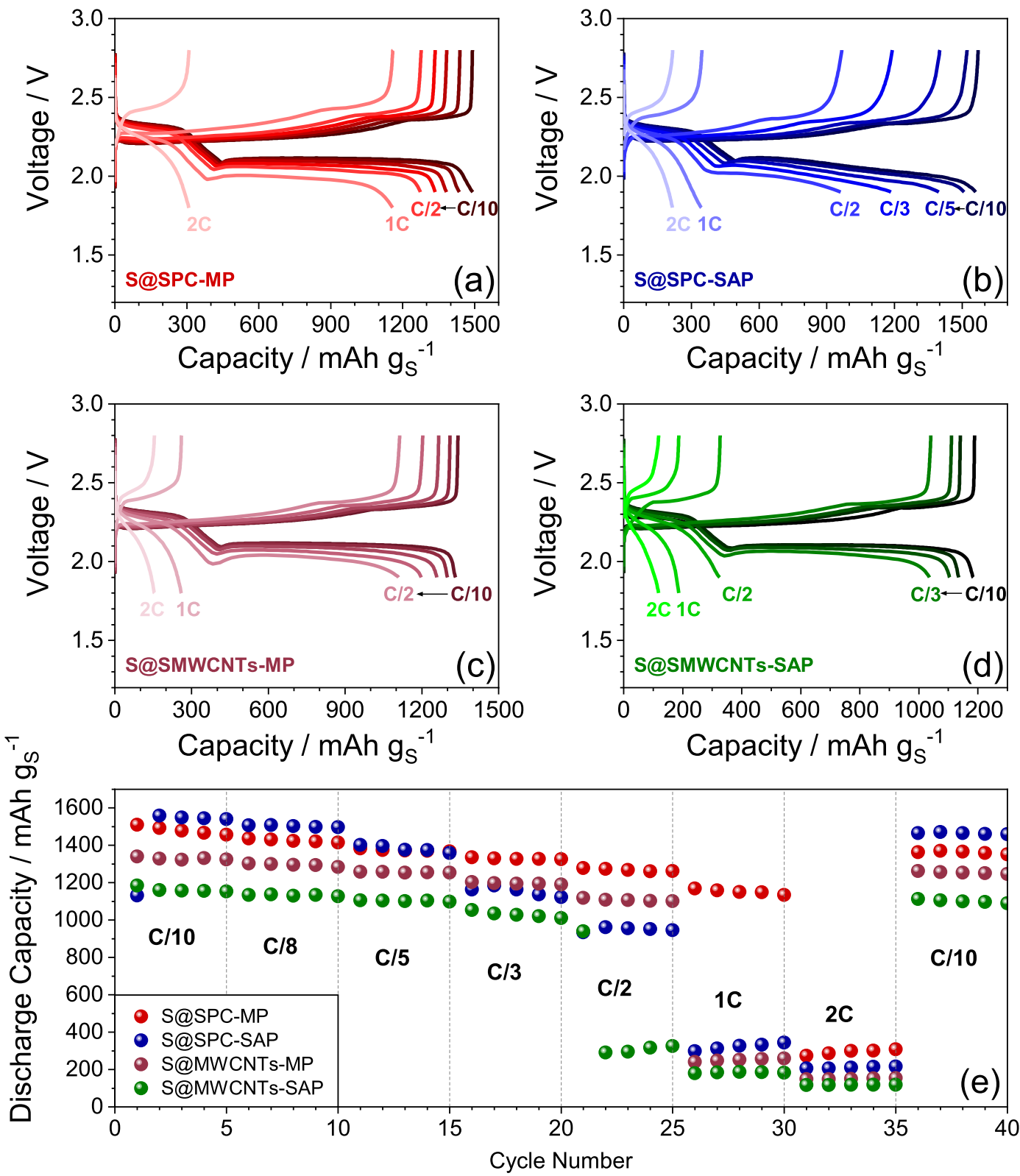

Fig. 6. (a-d) Voltage profiles and (e) cycling behavior of the (a) S@SPC-MP, (b) S@SPC-SAP, (c) S@MWCNTs-MP, and (d) S@MWCNTs-SAP electrodes in Li coincells studied at current rates increasing from $\mathrm{C} / 10$ to $2 \mathrm{C}\left(1 \mathrm{C}=1675 \mathrm{~mA} \mathrm{gs}^{-1}\right)$. Voltage range: $1.9-2.8 \mathrm{~V}$ from C/10 to $\mathrm{C} / 2$; $1.8-2.8 \mathrm{~V}$ from $1 \mathrm{C}$ to $2 \mathrm{C}$. Electrolyte solution: $1 \mathrm{~mol} \mathrm{~kg}_{\text {solvent }}^{-1} \mathrm{LiTFSI}, 1 \mathrm{~mol} \mathrm{~kg}$ solvent $\mathrm{LiNO}_{3}$ in DOL:DME 1:1 w/w. Temperature: $25^{\circ} \mathrm{C}$. Sulfur loading: from 1.7 to $2.4 \mathrm{mg} \mathrm{cm}^{-2}$ (see Tables S1 and S2 in the Supplementary data for details on the average sulfur mass loading over the electrodes, the corresponding electrolyte/sulfur ratio in the cells as well as the specific capacity values as referred to the $\mathrm{S}$ mass, $\mathrm{S}+\mathrm{C}$ mass in the composite, and $\mathrm{S}+\mathrm{C}+\mathrm{PVDF}$ mass in the electrode film).

decreasing the average particle size with respect to the MWCNTs, while the SAP strongly mitigated the effect of the carbon nature on the morphology. On the other hand, SPC remarkably enhanced the sulfur conversion kinetics compared to MWCNTs, thus enabling an outstanding maximum capacity of about $1500 \mathrm{mAh} \mathrm{gs}^{-1}$. Remarkably, such an improvement was not affected by the sulfur particle size within the electrode, thereby suggesting a crucial role played by the SPC on the polysulfide conversion. Therefore, the electrode prepared by MP using SPC (i.e., S@SPC-MP) was the preferred combination to improve the sulfur dispersion in the electrode and deliver a reversible capacity from 1500 to $1150 \mathrm{mAh} \mathrm{gS}_{\mathrm{S}}^{-1}$ within the wide current range from C/10 to $1 \mathrm{C}$ (where $1 \mathrm{C}=1675 \mathrm{~mA} \mathrm{~g}_{\mathrm{S}}^{-1}$ ). Besides, the electrode prepared by SAP exploiting the MWCNTs (S@MWCNTs-SAP) benefited from a morphology consisting of large sulfur particles ensuring a capacity retention as high as $69 \%$ after 150 charge/discharge cycles.

\section{Declaration of competing interest}

The authors declare that they have no known competing financial interests or personal relationships that could have appeared to influence the work reported in this paper.

\section{CRediT authorship contribution statement}

Daniele Di Lecce: Investigation, Visualization, Formal analysis, Writing - original draft. Vittorio Marangon: Investigation, Visualization, Formal analysis, Writing - original draft. Wenjia Du: Investigation, Formal analysis. Dan J.L. Brett: Supervision, Funding acquisition. Paul R. Shearing: Validation, Writing - review \& editing, Supervision, Project administration, Funding acquisition. Jusef Hassoun: Conceptualization, Validation, Writing - original draft, Writing - review \& 

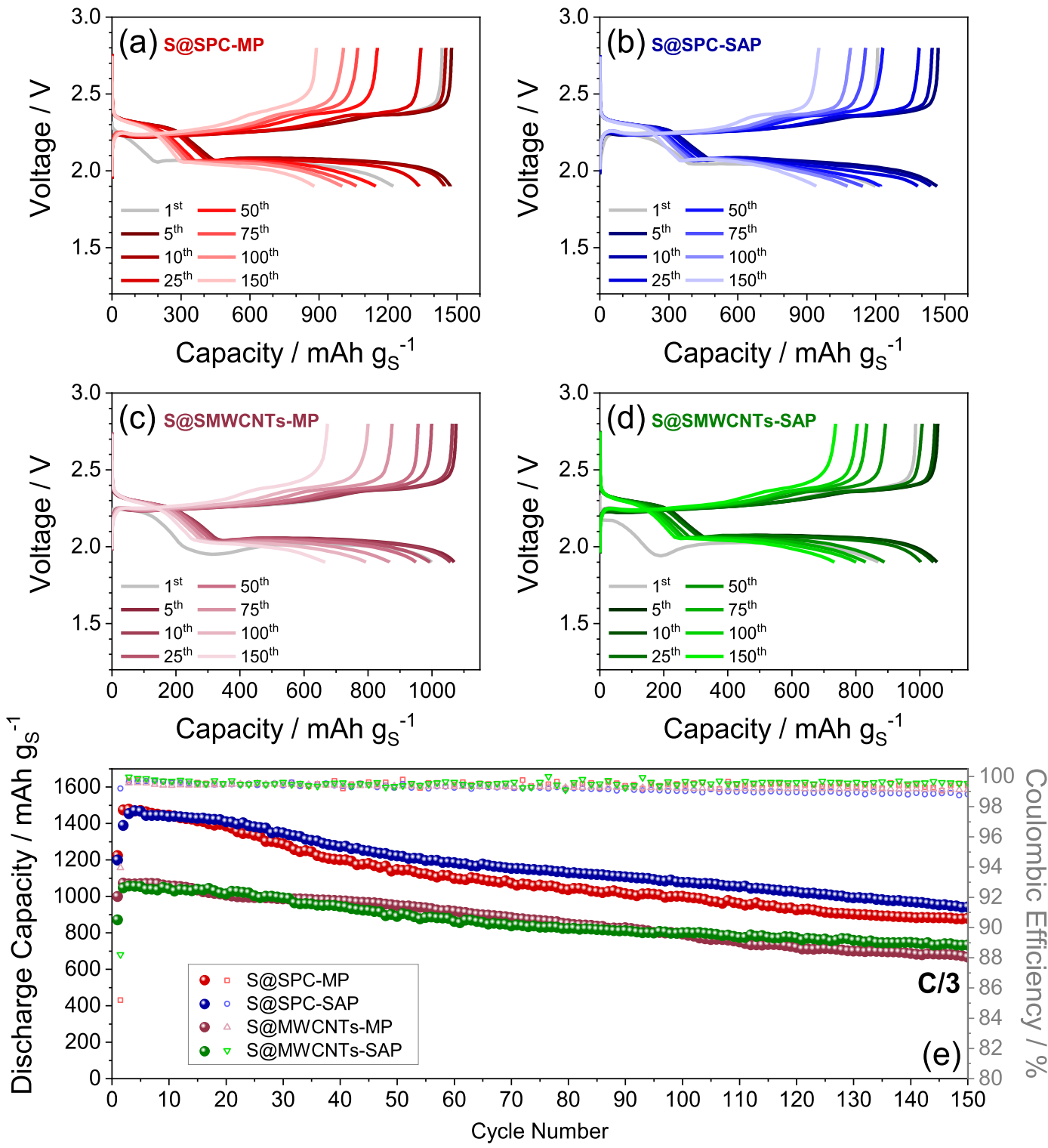

Fig. 7. (a-d) Voltage profiles and (e) cycling behavior with coulombic efficiency of the (a) S@SPC-MP, (b) S@SPC-SAP, (c) S@MWCNTs-MP, and (d) S@MWCNTsSAP electrodes in Li coin-cells studied at a constant current rate of $\mathrm{C} / 3\left(1 \mathrm{C}=1675 \mathrm{~mA} \mathrm{gs}^{-1}\right)$. Voltage range: 1.9-2.8 V. Electrolyte solution: $1 \mathrm{~mol} \mathrm{~kg}$ solvent $\mathrm{LiTFSI}^{-1}$ mol kg solvent $\mathrm{LiNO}_{3}$ in DOL:DME 1:1 w/w. Temperature: $25^{\circ} \mathrm{C}$. Sulfur loading: from 1.7 to $2.9 \mathrm{mg} \mathrm{cm}^{-2}$ (see Tables S1 and S3 in the Supplementary data for details on the average sulfur mass loading over the electrodes, the corresponding electrolyte/sulfur ratio in the cells as well as the specific capacity values as referred to the $\mathrm{S}$ mass, $\mathrm{S}+\mathrm{C}$ mass in the composite, and $\mathrm{S}+\mathrm{C}+$ PVDF mass in the electrode film).

editing, Supervision, Project administration, Funding acquisition.

\section{Acknowledgements}

This work was funded by the grant "Fondo di Ateneo per la Ricerca Locale (FAR) 2019", University of Ferrara, and performed within the collaboration project "Accordo di Collaborazione Quadro 2015" between University of Ferrara (Department of Chemical and Pharmaceutical Sciences) and Sapienza University of Rome (Department of Chemistry). The authors acknowledge funding from The Faraday Institution LiSTAR programme (FIRG014, EP/S003053/1). X-ray measurements were supported by funding from EPSRC (EP/K005030/1).

\section{Appendix A. Supplementary data}

Supplementary data to this article can be found online at https://doi. org/10.1016/j.jpowsour.2020.228424.

\section{References}

[1] A. Manthiram, S.-H. Chung, C. Zu, Lithium-sulfur batteries: progress and prospects, Adv. Mater. 27 (2015) 1980-2006, https://doi.org/10.1002/adma.201405115.

[2] D. Di Lecce, R. Verrelli, J. Hassoun, Lithium-ion batteries for sustainable energy storage: recent advances towards new cell configurations, Green Chem. 19 (2017) 3442-3467, https://doi.org/10.1039/C7GC01328K.

[3] S. Chung, A. Manthiram, Current status and future prospects of metal-sulfur batteries, Adv. Mater. 31 (2019) 1901125, https://doi.org/10.1002/ adma.201901125.

[4] R. Fang, S. Zhao, Z. Sun, D.-W. Wang, H.-M. Cheng, F. Li, More reliable lithiumsulfur batteries: status, solutions and prospects, Adv. Mater. 29 (2017) 1606823, https://doi.org/10.1002/adma.201606823.

[5] A. Bhargav, J. He, A. Gupta, A. Manthiram, Lithium-sulfur batteries: attaining the critical metrics, Joule 4 (2020) 285-291, https://doi.org/10.1016/j. joule.2020.01.001.

[6] L. Carbone, S.G.S.G. Greenbaum, J. Hassoun, Lithium sulfur and lithium oxygen batteries: new frontiers of sustainable energy storage, Sustain. Energy Fuels 1 (2017) 228-247, https://doi.org/10.1039/C6SE00124F.

[7] M.R. Busche, P. Adelhelm, H. Sommer, H. Schneider, K. Leitner, J. Janek, Systematical electrochemical study on the parasitic shuttle-effect in lithium-sulfur- 
cells at different temperatures and different rates, J. Power Sources 259 (2014) 289-299, https://doi.org/10.1016/j.jpowsour.2014.02.075.

[8] Q. Pang, X. Liang, C.Y. Kwok, L.F. Nazar, Advances in lithium-sulfur batteries based on multifunctional cathodes and electrolytes, Nat. Energy 1 (2016) 16132, https://doi.org/10.1038/nenergy.2016.132.

[9] X. Yu, H. Wu, J.H. Koo, A. Manthiram, Tailoring the pore size of a polypropylene separator with a polymer having intrinsic nanoporosity for suppressing the polysulfide shuttle in lithium-sulfur batteries, Adv. Energy Mater. 10 (2020) 1902872, https://doi.org/10.1002/aenm.201902872.

[10] H.M. Kim, H.-H. Sun, I. Belharouak, A. Manthiram, Y.-K. Sun, An alternative approach to enhance the performance of high sulfur-loading electrodes for Li-S batteries, ACS Energy Lett. 1 (2016) 136-141, https://doi.org/10.1021/ acsenergylett.6b00104.

[11] M. Li, Y. Wan, J.K. Huang, A.H. Assen, C.E. Hsiung, H. Jiang, Y. Han, M. Eddaoudi, Z. Lai, J. Ming, L.J. Li, Metal-organic framework-based separators for enhancing LiS battery stability: mechanism of mitigating polysulfide diffusion, ACS Energy Lett. 2 (2017) 2362-2367, https://doi.org/10.1021/acsenergylett.7b00692.

[12] S. Zhang, K. Ueno, K. Dokko, M. Watanabe, Recent advances in electrolytes for lithium-sulfur batteries, Adv. Energy Mater. 5 (2015) 1500117, https://doi.org/ 10.1002/aenm.201500117.

[13] H. Shin, M. Agostini, I. Belharouak, J. Hassoun, Y.-K. Sun, High-power lithium polysulfide-carbon battery, Carbon 96 (2016) 125-130, https://doi.org/10.1016/j carbon.2015.09.034.

[14] R. Fang, S. Zhao, P. Hou, M. Cheng, S. Wang, H.-M. Cheng, C. Liu, F. Li, 3D interconnected electrode materials with ultrahigh areal sulfur loading for Li-S batteries, Adv. Mater. 28 (2016) 3374-3382, https://doi.org/10.1002/ adma.201506014.

[15] A. Benítez, Á. Caballero, E. Rodríguez-Castellón, J. Morales, J. Hassoun, The role of current collector in enabling the high performance of Li/S battery, ChemistrySelect 3 (2018) 10371-10377, https://doi.org/10.1002/slct.201802529.

[16] H.-J. Peng, W.-T. Xu, L. Zhu, D.-W. Wang, J.-Q. Huang, X.-B. Cheng, Z. Yuan, F. Wei, Q. Zhang, 3D carbonaceous current collectors: the origin of enhanced cycling stability for high-sulfur-loading lithium-sulfur batteries, Adv. Funct. Mater 26 (2016) 6351-6358, https://doi.org/10.1002/adfm.201602071.

[17] P. Han, S.-H. Chung, C.-H. Chang, A. Manthiram, Bifunctional binder with nucleophilic lithium polysulfide immobilization ability for high-loading, highthickness cathodes in lithium-sulfur batteries, ACS Appl. Mater. Interfaces 11 (2019) 17393-17399, https://doi.org/10.1021/acsami.9b02399.

[18] M. Shaibani, M.S. Mirshekarloo, R. Singh, C.D. Easton, M.C.D. Cooray, N. Eshraghi, T. Abendroth, S. Dörfler, H. Althues, S. Kaskel, A.F. Hollenkamp, M.R. Hill, M. Majumder, Expansion-tolerant architectures for stable cycling of ultrahighloading sulfur cathodes in lithium-sulfur batteries, Sci. Adv. 6 (2020), eaay2757, https://doi.org/10.1126/sciadv.aay2757.

[19] X. Ji, K.T. Lee, L.F. Nazar, A highly ordered nanostructured carbon-sulphur cathode for lithium-sulphur batteries, Nat. Mater. 8 (2009) 500-506, https://doi. org/10.1038/nmat2460.

[20] G. Zheng, Y. Yang, J.J. Cha, S.S. Hong, Y. Cui, Hollow carbon nanofiberencapsulated sulfur cathodes for high specific capacity rechargeable lithium batteries, Nano Lett. 11 (2011) 4462-4467, https://doi.org/10.1021/nl2027684.

[21] J. Hassoun, J. Kim, D.-J. Lee, H.-G. Jung, S.-M. Lee, Y.-K. Sun, B. Scrosati, A contribution to the progress of high energy batteries: a metal-free, lithium-ion, silicon-sulfur battery, J. Power Sources 202 (2012) 308-313, https://doi.org/ 10.1016/j.jpowsour.2011.11.060.

[22] J. Kim, D.J. Lee, H.G. Jung, Y.K. Sun, J. Hassoun, B. Scrosati, An advanced lithiumsulfur battery, Adv. Funct. Mater. 23 (2013) 1076-1080, https://doi.org/10.1002 adfm.201200689.

[23] H. Pan, J. Chen, R. Cao, V. Murugesan, N.N. Rajput, K.S. Han, K. Persson, L. Estevez, M.H. Engelhard, J.-G. Zhang, K.T. Mueller, Y. Cui, Y. Shao, J. Liu, Nonencapsulation approach for high-performance Li-S batteries through controlled nucleation and growth, Nat. Energy 2 (2017) 813-820, https://doi.org/10.1038/ s41560-017-0005-z.

[24] D. Di Lecce, V. Marangon, A. Benítez, Á. Caballero, J. Morales, E. RodríguezCastellón, J. Hassoun, High capacity semi-liquid lithium sulfur cells with enhanced reversibility for application in new-generation energy storage systems, J. Power Sources 412 (2019) 575-585, https://doi.org/10.1016/j.jpowsour.2018.11.068.

[25] L. Carbone, T. Coneglian, M. Gobet, S. Munoz, M. Devany, S. Greenbaum, J. Hassoun, A simple approach for making a viable, safe, and high-performances lithium-sulfur battery, J. Power Sources 377 (2018) 26-35, https://doi.org/ 10.1016/j.jpowsour.2017.11.079.

[26] H.-J. Peng, J.-Q. Huang, X.-B. Cheng, Q. Zhang, Review on high-loading and highenergy lithium-sulfur batteries, Adv. Energy Mater. 7 (2017) 1700260, https://doi. org/10.1002/aenm.201700260.

[27] J. Zhang, H. Huang, J. Bae, S.-H. Chung, W. Zhang, A. Manthiram, G. Yu, Nanostructured host materials for trapping sulfur in rechargeable Li-S batteries: structure design and interfacial chemistry, Small Methods 2 (2018) 1700279 , https://doi.org/10.1002/smtd.201700279.

[28] R. Xu, J.C.M. Li, J. Lu, K. Amine, I. Belharouak, Demonstration of highly efficient lithium-sulfur batteries, J. Mater. Chem. A. 3 (2015) 4170-4179, https://doi.org/ 10.1039/C4TA06641C.

[29] V. Marangon, J. Hassoun, Sulfur loaded by nanometric tin as a new electrode for high-performance lithium/sulfur batteries, Energy Technol. 1900081 (2019) 1900081, https://doi.org/10.1002/ente.201900081.

[30] H. Tan, S. Wang, D. Tao, Z. Yang, Acetylene black/sulfur composites synthesized by a solution evaporation concentration crystallization method and their electrochemical properties for $\mathrm{Li} / \mathrm{S}$ batteries, Energies 6 (2013) 3466-3480, https://doi.org/10.3390/en6073466.
[31] Y.-T. Weng, H. Wang, R.-C. Lee, C.-Y. Huang, S.-S. Huang, M. Abdollahifar, L.M. Kuo, B.-J. Hwang, C.-L. Kuo, Y. Cui, N.-L. Wu, Efficient synthesis of high-sulfurcontent cathodes for high-performance Li-S batteries based on solvothermal polysulfide chemistry, J. Power Sources 450 (2020) 227676, https://doi.org/ 10.1016/j.jpowsour.2019.227676.

[32] L. Carbone, J. Peng, M. Agostini, M. Gobet, M. Devany, B. Scrosati, S. Greenbaum, J. Hassoun, Carbon composites for a high-energy lithium-sulfur battey with a glyme-based electrolyte, ChemElectroChem 4 (2017) 209-215, https://doi.org/ 10.1002/celc.201600586.

[33] A. Yermukhambetova, C. Tan, S.R. Daemi, Z. Bakenov, J.A. Darr, D.J.L. Brett, P. R. Shearing, Exploring 3D microstructural evolution in Li-Sulfur battery electrodes using in-situ X-ray tomography, Sci. Rep. 6 (2016) 35291, https://doi.org/ 10.1038/srep35291.

[34] C. Tan, T.M.M. Heenan, R.F. Ziesche, S.R. Daemi, J. Hack, M. Maier, S. Marathe, C. Rau, D.J.L. Brett, P.R. Shearing, Four-dimensional studies of morphology evolution in lithium-sulfur batteries, ACS Appl. Energy Mater. 1 (2018) 5090-5100, https://doi.org/10.1021/acsaem.8b01148.

[35] D. Di Lecce, S. Levchenko, F. Iacoviello, D.J.L. Brett, P.R. Shearing, J. Hassoun, Xray nano-computed tomography of electrochemical conversion in lithium-ion battery, ChemSusChem 12 (2019) 3550-3561, https://doi.org/10.1002/ cssc. 201901123.

[36] L. Zielke, C. Barchasz, S. Waluś, F. Alloin, J.-C. Leprêtre, A. Spettl, V. Schmidt, A. Hilger, I. Manke, J. Banhart, R. Zengerle, S. Thiele, Degradation of Li/S battery electrodes on 3D current collectors studied using X-ray phase contrast tomography, Sci. Rep. 5 (2015) 10921, https://doi.org/10.1038/srep10921.

[37] B. Meyer, Elemental sulfur, Chem. Rev. 76 (1976) 367-388, https://doi.org/ 10.1021/cr60301a003.

[38] O.O. Taiwo, D.P. Finegan, J. Gelb, C. Holzner, D.J.L. Brett, P.R. Shearing, The use of contrast enhancement techniques in X-ray imaging of lithium-ion battery electrodes, Chem. Eng. Sci. 154 (2016) 27-33, https://doi.org/10.1016/j. ces.2016.04.023.

[39] T.M.M. Heenan, J.J. Bailey, X. Lu, J.B. Robinson, F. Iacoviello, D.P. Finegan, D.J. L. Brett, P.R. Shearing, Three-phase segmentation of solid oxide fuel cell anode materials using lab based X-ray nano-computed tomography, Fuel Cell. 17 (2017) 75-82, https://doi.org/10.1002/fuce.201600176.

[40] C. Tan, M.D.R. Kok, S.R. Daemi, D.J.L. Brett, P.R. Shearing, Three-dimensional image based modelling of transport parameters in lithium-sulfur batteries, Phys. Chem. Chem. Phys. 21 (2019) 4145-4154, https://doi.org/10.1039/C8CP04763D.

[41] B. Münch, L. Holzer, Contradicting geometrical concepts in pore size analysis attained with electron microscopy and mercury intrusion, J. Am. Ceram. Soc. 91 (2008) 4059-4067, https://doi.org/10.1111/j.1551-2916.2008.02736.x.

[42] A. Benítez, D. Di Lecce, Á. Caballero, J. Morales, E. Rodríguez-Castellón, J. Hassoun, Lithium sulfur battery exploiting material design and electrolyte chemistry: 3D graphene framework and diglyme solution, J. Power Sources 397 (2018) 102-112, https://doi.org/10.1016/j.jpowsour.2018.07.002.

[43] L. Carbone, P.T. Moro, M. Gobet, S. Munoz, M. Devany, S.G. Greenbaum, J. Hassoun, Enhanced lithium oxygen battery using a glyme electrolyte and carbon nanotubes, ACS Appl. Mater. Interfaces 10 (2018) 16367-16375, https://doi.org/ 10.1021/acsami.7b19544.

[44] D. Di Lecce, P. Andreotti, M. Boni, G. Gasparro, G. Rizzati, J.-Y. Hwang, Y.-K. Sun, J. Hassoun, Multiwalled carbon nanotubes anode in lithium-ion battery with $\mathrm{LiCoO}_{2}, \mathrm{Li}\left[\mathrm{Ni}_{1 / 3} \mathrm{Co}_{1 / 3} \mathrm{Mn}_{1 / 3}\right] \mathrm{O}_{2}$, and $\mathrm{LiFe}_{1 / 4} \mathrm{Mn}_{1 / 2} \mathrm{Co}_{1 / 4} \mathrm{PO}_{4}$ cathodes, ACS Sustain. Chem. Eng. 6 (2018) 3225-3232, https://doi.org/10.1021/ acssuschemeng.7b03395.

[45] J. Lee, A.S. Teja, Characteristics of lithium iron phosphate $\left(\mathrm{LiFePO}_{4}\right)$ particles synthesized in subcritical and supercritical water, J. Supercrit. Fluids 35 (2005) 83-90, https://doi.org/10.1016/j.supflu.2004.12.005.

[46] G. Li, J. Sun, W. Hou, S. Jiang, Y. Huang, J. Geng, Three-dimensional porous carbon composites containing high sulfur nanoparticle content for highperformance lithium-sulfur batteries, Nat. Commun. 7 (2016) 10601, https://doi. org/10.1038/ncomms10601.

[47] A. Benítez, D. Di Lecce, G.A. Elia, Á. Caballero, J. Morales, J. Hassoun, A Lithiumion battery using a 3D-array nanostructured graphene-sulfur cathode and a silicon oxide-based anode, ChemSusChem 11 (2018) 1512-1520, https://doi.org/ $10.1002 /$ cssc. 201800242.

[48] V. Marangon, D. Di Lecce, F. Orsatti, D.J.L. Brett, P.R. Shearing, J. Hassoun, Investigating high-performance sulfur-metal nanocomposites for lithium batteries, Sustain. Energy Fuels 4 (2020) 2907-2923, https://doi.org/10.1039/ D0SE00134A.

\section{Glossary}

3D: three-dimensional

BHT: butylated hydroxytoluene

$C C D$ : charge-coupled device

$C T$ : computed tomography

DME: 1,2-dimethoxyethane

DOL: 1,3-dioxolane

$E D S$ : energy dispersive X-ray spectroscopy

FWHM: full width at half maximum

ICSD: Inorganic Crystal Structure Database

Li-S: lithium-sulfur

LiTFSI: lithium bis(trifluoromethanesulfonyl)imide

$M P$ : melting procedure

MWCNTs: multiwalled carbon nanotubes 
NMP: N-methyl-2-pyrrolidone

$P S D$ : particle size distribution

$P V D F$ : polyvinylidene fluoride

$S A P$ : solvent-assisted procedure

$S$-C: sulfur-carbon
SEI: solid electrolyte interphase

SEM: scanning electron microscopy

SPC: super P carbon black

SS: stainless steel

$X R D$ : X-ray diffraction 